\title{
Analysis of Business English Translation in Hospitality Industry Based on Skopos Theory
}

\author{
Jialin Zhong
}

\begin{abstract}
This thesis analyzes a purpose-oriented business translation, Skopos theory, in the hospitality industry. The topics are related to the use of language and branding strategies. This thesis aims to propose a holistic approach to business translation for the hospitality business based on the theory and localization project. Different U.S. and Chinese business brands will be used as examples. Following the criticisms of Skopos theory, the business translator's responsibilities will be specified within a localization project in the process of international brand expansion.
\end{abstract}

Index Terms-Business translation, skopos theory, hospitality management, branding strategies.

\section{INTRODUCTION}

In the increasingly internationalized marketplace, translation has played a significant role in business trade between top trading powers. The rising volume and speed of international commerce have resulted in considerable demand in business translation and related services [1] (Dunne \& Dunne, 2011), especially between US-China trading businesses. From the start of $21^{\text {st }}$ century, the service industry has proliferated in emerging and developed countries. It is $66 \%$ in the U.S. GDP and $32 \%$ in China's GDP [2] (Datta, 2001). The Chinese mainland has become one of the most attractive markets with billions of potential consumers, which appeals to many Western corporates [3] (Reid \& Walsh, 2003). Meanwhile, this brand expansion is mutual. Chinese hospitality brands are now expanding to the Western marketplace as, such as the famous Chinese cuisine brand (e.g., Da Dong Roast Duck Restaurant) and trendy Chinese tea brand (e.g., Heytea).

Despite satisfactory interests in business translation between Chinese and English, the topic of translation in tourism and hospitality management gained less attention. An ideal business English translation should take business purposes and effects into consideration, beyond accurate linguistic expressions. This thesis aims to address the theoretical gap by discussing how to ensure the translation text aligns with the company's brand strategy.

\section{THEORETICAL BACKGROUND}

Skopos theory is a functional and sociocultural approach in translation studies proposed by Hans Vemeer [4] (Du, 2012). The translation is considered a specific form of human action that is "intentional and purposeful" based on this theory [5] (Nord, 2018). Compared with all schools of translation thought, Skopos theory focuses on the intended purpose of translation text [6] (Baker Kumar \& Saldanha, 2009). Skopos theory is particularly suitable for business translation because it inherently prioritizes business intentions and objectives over linguistic equivalence.

Aside from the intention, culture is another critical component in the Skopos theory. A foreign concept can be understood more easily when compared with our own culture [7] (Eisenman, 2007). A translator should be the one who can interpret the culture of the source language and convey the meaning in the target culture, especially the core meaning of brand essence. Therefore, the inequivalence in culture concept can be a challenge in business translation studies.

\section{Skopos THEORY APPLIED IN HoSPITALITY BUSINESS TRANSLATION}

Both U.S. and Chinese hospitality brands may face cultural inequivalence regarding branding strategies while first entering an unfamiliar foreign market. The main challenge is how to precisely elaborate the brand's philosophy to the market in which it operates when the brand concept statement is often a simple phrase. As for the internal branding, the challenge is how to convey the proper brand concept to Chinese/ U.S. branches along with managerial suggestions to employee training. Another one is how to send the appropriate brand image to the target audience to encourage purchase, which has to do with the external branding.

Internal branding is the indispensable "underpinning of a successful brand that has longevity, great competitive strength, and high financial value" [8] (Giehl \& LePla, 2012). The optimal translating purpose for internal branding should be to improve employees' brand perceptions and instruct employees to perform.

The concept of "Guestology" in the hospitality industry is pioneering, invented by The Walt Disney corporation. From a linguistic perspective, portmanteaus words are prevalent in English as it is a synthetic language featured by abundant affixes and suffixes [9] (Li, 1984). "Guestology" is composed of the word "guest" and a suffix "logy." Chinese is "an extremely analytic language" [9] ( $\mathrm{Li}, 1984)$, characterized by invariable word types, so a newly designed word like "Guestology" requires translators to go beyond the word itself. The concept asks hospitality employees to treat customers as if they were guests in employees' own homes, and the management team needs to operate in the light of 
customer behaviors [10] (Ford \& Sturman, 2018). An international hotel chain would face challenges of conveying an accurate concept of "Guestology" to its branches in China when there are no equivalent words or concepts. The underlying purpose of this translation activity is to carry out "Guestology" at both front-line employees and senior management levels. Therefore, a translator has to cooperate with the management team to add necessary notes in training brochures and operational manuals.

Grand Hyatt holds on delivering enhanced services, and location near-identical attractions with wide-open spaces. "Authentic luxury" is the brand essence of Grand Hyatt [11] (King \& So, 2015). However, this idea does not originate from Chinese culture, so employees of the Chinese Grand Hyatt branches may encounter difficulties in understanding the implications of "authentic luxury" as to perform specific roles [11] (King \& So, 2015). Without a thorough understanding, the Chinese employees would easily confuse Grand Hyatt with other luxury hotel brands. In this case, the ultimate purpose of translating "authentic luxury" is to align employee behavior with the brand culture, which is challenging as Grand Hyatt's country of origin (the U. S.) is foreign to the Chinese mainland market.

Considered not only as of the business identity but also as the company's philosophy and personality, the brand external images can function as one of the most effective strategies in terms of communication [12] (Hillenbrand, Alcauter, Cervantes, \& Barrios, 2013). Two successful Chinese renderings of brand names will be discussed. The brands are Coca-Cola and Marriott International Inc., both initially created in the U.S.

A popular carbonated beverage invented by $\mathrm{Mr}$. Pemberton in 1866, the name of Coca-Cola was coined by his business partner, Mr. Robertson, based on two vital ingredients, coca leaf and kola nut [13] (Tamony, 1969). Marriott's name is derived from the founder John Willard Marriott and his wife. According to the western custom, John Willard Marriott named the hotel after his family name. Etymologically speaking, there are no deeper connotations or meanings in Coca-Cola and Marriott's name, which is typically not the Chinese way to name a brand. Coca-Cola and Marriott International Inc., has obtained extensive popularity in China. Coca-Cola is one of top seven companies in China's bottled-water market [14] (Finlayson, 2005) and Marriott has been enlarged into 64 operating hotels in China [15] (Wong \& Wickham, 2015). The successes of them partly thanks to the smart choices of Chinese names.

Coca-Cola's Chinese name, "Ke Kou Ke Le" literally means "tastes good and makes one happy" has been regarded as a widely known good translation example [16] (Ran, 2010). Its success was first achieved phonetically. Easy to read and remember from the phonetics, the sounds of "Ke Kou Ke Le" in Chinese are almost perfectly matched with its English name Coca-Cola [16] (Ran, 2010). In doing so, the original phonetic feature is well kept, and the "lost in translation" is well prevented. Customers have no trouble in identifying the brand by its Chinese sounds alone. Although its Chinese name does not equal the original semantic meaning of CocaCola, a more aural effect was added to the Chinese one with a positive feeling of tasty and delight that even its original name does not contain [16] (Ran, 2010). Taking a more profound step into the cultural perspective, Coca-Cola embraces an environment full of the passion for refreshing the world and the desire to make a difference [17] (Svendsen, 2013). The Chinese translation also resonates well with its authentic cooperate culture by its sunny image and its red color, which happens to be the favorite in the Chinese tradition, representing happiness, joy, prosperity, and passion [18] (Sang \& Zhang, 2008). Its early successful marketing outcomes in China partly because its name made a shift to align with the target customers' cultural identity.

At first, Marriott was translated as "Ma Li Ao Te," which was not appealing at all, by simply using transliteration. The current Chinese name, "Wan Hao," is the result of transliteration in Cantonese. The semantic meaning of its translation shows the thoroughly selective process in the sense of lexis picking. The Chinese characters of both "Wa" and "Hao" represent positive symbolization, like "rich," "wealth," "heroic," and "outstanding." Similar to Coca-Cola, Marriott takes a further step with added interpretation in its Chinese name to create a positive connotation in the target culture. The goal behind this is a formation of its positive brand image and a promotion of its sales, particularly targeting the luxury hospitality market of mainland China. "Wan Hao," interpreted as "wealthy elites," can function as a label pitched to the Marriott brand, representing the exquisite and luxury experience that the hotel will provide to its customers. "Wan Hao" potentially delivers a sense of elitism in the minds of Chinese customers. Whenever people think of booking a room at "Wan Hao", they tend to believe that as elites themselves, they are well deserved to enjoy the exceptional services provided by the elite brand in the lodging industry. Based on Coca-Cola and Marriot's examples, if it is possible to find a translation that sounds like the original name and has an auspicious and appropriate meaning, that would be the ideal rendering. However, if the similar-sounding syllables cannot be found, meaning should take precedence.

Menu, the most important sales tool, influences customers' purchase decisions and gives people an overall impression of the brand itself [19] (Pavesic, 2005). An interview with the general manager of MÖGE TEE, an international Chinese milk tea brand, in Philadelphia has been undertaken to gain insights. Until now, MÖGE TEE has 360 outlets worldwide, including China, the United States, Australia, and Southeast Asia. Its current English menu is thoroughly copied from the headquarters without any business translation polishing. When the brand expands to other markets, it faces difficulties in translating names of beverages, some of which are quite authentic Chinese names. The current tea beverages are simply transliteration names that fail to offer efficient communication to customers. For the whole series of Chinese tea beverages, this thesis proposes two ways to translate Chinese tea names.

Firstly, some of the beverage items can be featured with notes below each name. For example, "Da Hong Pao Milk Tea" is confusing for non-Chinese customers as they never know what Da Hong Pao tea exactly is. Since this type of tea is quite unique, which can differentiate MÖGE TEE from other milk tea stores, the suggestion is to change this item into a signature product and adding a brief description to highlight it. Instead of merely adopting transliteration, the 
English description is needed for marketing functions. For instance, the short description on the menu could be "Da Hong Pao, the tea of the highest quality in China, is exclusively reserved for honored guests."

Secondly, the rest transliteration names should be changed into descriptive and evocative names according to the unique taste of each type of tea. The menu serves as a business card that markets the brand rather than a list of linguistically accurate renderings. The current translated names of MÖGE TEE's products only create difficulties for non-Chinese customers to order. Studies have shown that the more a higher expectation of the descriptively-named foods, the more likely customers are to rate it as more attractive and tastier [20] (Wansink, Van Ittersum, \& Painter, 2005). For example, "Cheese foam Dongding Oolong tea" can be replaced by "Light Honey Oolong Tea."

\section{LIMITATIONS OF SKOPOS THEORY AND ITS POTENTIAL SOLUTION}

There is an inherent cultural imperialism tendency in the Skopos theory. It regards the culture of the target language as the center of translation. It is often criticized for "changing or even betraying the originals" [5] (Nord, 2018). For instance, by applying Skopos theory, "Dongding Oolong Tea" is transformed into a descriptive name just because the initial name is pointless for a part of the customers so the theory may overlook the richness of source texts' meaning. Another limitation is that the Skopos theory requires a translator to go beyond a freelance translator's role. Still, a professional translator may not always have the authority to make certain decisions since, for instance, a translator alone cannot decide which menu items should be featured or which items' names should be changed.

With the emergence of the Web and theoretical foundation of Skopos, part of the business translation services has evolved into commercial translation projects called localization projects [21] (Somers, 2003). The localization theory is initially "developed for the area of technical translation" [22] (Odacıoglu, 2017). This localization theory suits the language requirements, and also considers the complicated management environment, bringing the entire translation process in house.

The responsibilities of each role in the localization team must be well defined. The localization project team includes professional or freelance translators, a project manager, a localization engineer, etc. [23] (Gambier \& Van Doorslaer, 2010). A project manager is in the supervision of the whole project. The freelance translator would not be bothered by the business purpose too much at the very beginning since his job is merely contents translation at first. Later, however, localization may require the translator to "perform extremely technical and demanding administrative tasks "[23] (Gambier \& Van Doorslaer, 2010).

The localization project, integrated target-oriented translation with the technology tools, can remedy a major limitation of Skopos theory, overlooking the richness of the meaning of the source text (or losing the advantages of linguistic equivalence). With the applications of machine translation and linguistic database (word-to-word equivalence) [22] (Odacioğlu, 2017), the original text is highlighted at the first step of localization theory. This teamwork can properly preserve the commercially valuable cultural elements in the source texts. Using managerial methods, the name of "Da Hong Pao" in the last case has been reserved, which is a symbol of the culture from the source text. By implementing the localization project, the project manager can identify such a commercially valuable element and further put marketing efforts in it instead of merely paraphrasing it into an evocative name. Within this multifunctional localization team, each member must closely cooperate. It is necessary to be broad-minded and inclusive so that they can put forward constructive opinions while achieving the optimal goals.

\section{CONCLUSION}

Appling Skopos theory to the translation of international brands plays a decisive role in the global expansion of a corporate. Translators need to understand not only English but also hospitality management comprehensively. The lack of professional knowledge may hinder the credibility of translation. Cultural differences exist in different countries, so the culture inequivalence poses threats in hospitality brand strategy during an international brand's expansion. The corporate's external and internal branding faces multiple challenges during translation. Skopos theory also has limitations, such as overlooking the richness of source texts and overestimating a professional translator's ability and authority. While, a multi-functional localization team can make up for the imparity of the language-translation of Skopos theory, and the cooperation and coordination among the project members can achieve a more accurate and reasonable translation.

\section{REFERENCES}

[1] K. J. Dunne and E. S. Dunne, Translation and Localization Project Management: The Art of The Possible, John Benjamins Publishing, 2011.

[2] M. Datta, The Significance and Growth of the Tertiary Sector: Indian Economy, 1950-97, Northern Book Centre, 2001.

[3] D. M. Reid and J. Walsh, "Market entry decisions in China," Thunderbird International Business Review, vol. 45, no. 3, pp. 289312, 2003.

[4] X. Du, "A brief introduction of Skopos theory," Theory \& Practice in Language Studies, vol. 2, no. 10, 2012.

[5] C. Nord, Translating as a Purposeful Activity: Functionalist Approaches Explained, Routledge, 2018.

[6] M. Baker and G. Saldanha, Routledge Encyclopedia of Translation Studies, Routledge, 2009.

[7] J. Eisenman, China and the Developing World: Beijing's Strategy for the Twenty-First Century, ME Sharpe, 2007.

[8] W. Giehl and F. J. LePla, Create a Brand That Inspires: How to Sell, Organize and Sustain Internal Branding, Author House, 2012.

[9] C. N. Li, "From verb-medial analytic language to verb-final synthetic language: A case of typological change," presented at the Annual Meeting of the Berkeley Linguistics Society, 1984.

[10] R. C. Ford and M. C. Sturman, Managing Hospitality Organizations. Achieving Excellence in the Guest Experience, SAGE Publications, 2018.

[11] C. King and K. K. F. So, "Enhancing hotel employees' brand understanding and brand-building behavior in China," Journal of Hospitality \& Tourism Research, vol. 39, no. 4, pp. 492-516, 2015.

[12] P. Hillenbrand, S. Alcauter, J. Cervantes, and F. Barrios, "Better branding: Brand names can influence consumer choice," Journal of Product \& Brand Management, 2013.

[13] P. Tamony, "Coca-Cola: The most-lawed name," Names, vol. 17, no. 4, pp. 278-283, 1969. 
[14] D. Finlayson, "Market development of bottled waters," in Technology of Bottled Water, 2nd ed. D. Senior and N. Dege Eds. 2005, p. 6.

[15] T. Wong and M. Wickham, "An examination of Marriott's entry into the Chinese hospitality industry: A brand equity perspective," Tourism Management, vol. 48, pp. 439-454, 2015.

[16] S. Ran, "Chinese translation of Coca Cola: Analysis and enlightenment," Asian Culture and History, vol. 2, no. 2, p. 213, 2010.

[17] S. Svendsen, Refresh. Create. Inspire. The Mission, Vision and Values Behind the Coca-Cola Company and the Digital Marketing Strategies of the" Open Happiness" Campaign.

[18] J. Sang and G. Zhang, "Communication across languages and cultures: A perspective of brand name translation from English to Chinese," Journal of Asian Pacific Communication, vol. 18, no. 2, pp. 225-246, 2008.

[19] D. Pavesic, The Psychology of Menu Design: Reinvent Your' Silent Salesperson' to Increase Check Averages and Guest Loyalty, 2005.

[20] B. Wansink, K. Ittersum, and J. E. Painter, "How descriptive food names bias sensory perceptions in restaurants," Food Quality and Preference, vol. 16, no. 5, pp. 393-400, 2005.
[21] H. Somers, Computers and Translation: A Translator's Guide, John Benjamins Publishing, 2003.

[22] M. C. Odacioğlu, Integrated Localization Theory of Translation Studies, 2017.

[23] Y. Gambier and L. Doorslaer, Handbook of Translation Studies, John Benjamins Publishing, 2010.

[24] L. C. Dong and M. M. Helms, "Brand name translation model: A case analysis of US brands in China," Journal of Brand Management, vol. 9, no. 2, pp. 99-115, 2001.

[25] Q. Xiao, J. W. O'Neill, and H. Wang, "International hotel development: A study of potential franchisees in China," International Journal of Hospitality Management, vol. 27, no. 3 pp. 325-336, 2008.

Copyright $(\odot 2020$ by the authors. This is an open access article distributed under the Creative Commons Attribution License which permits unrestricted use, distribution, and reproduction in any medium, provided the original work is properly cited (CC BY 4.0). 